\title{
Correction to: Prevalence and correlates of transactional sex among women of low socioeconomic status in Portland, OR
}

Timothy W. Menza ${ }^{1,2,3^{*}} \mathbb{D}$, Lauren Lipira ${ }^{4}$, Amisha Bhattarai ${ }^{4}$, Victoria Cali-De Leon ${ }^{4}$ and E. Roberto Orellana ${ }^{4}$

\section{Correction to: BMC Women's Health (2020) 20:219 https://doi.org/10.1186/s12905-020-01088 $-1$}

Following publication of the original article [1], we were notified of a typo in the 4th paragraph of the "Statistical analyses" section:

- "We computed the variance inflation factor (VIF) and tolerance (1/VIF) for each of the ten predictors included in Model 4 to assess for collinearity. All tolerance values were less than 0.1 , indicating that each predictor was unlikely to be a linear combination of the others."

The word less should actually read greater.

\section{Author details}

${ }^{1}$ HIV/STD/TB Section, Public Health Division, Oregon Health Authority, 800 NE Oregon Street, Portland, OR 97232, USA. ${ }^{2}$ Oregon Health and Sciences University (OHSU), Portland, OR, USA. ${ }^{3}$ Multnomah County Health Department, Portland, OR, USA. ${ }^{4}$ Portland State University, Portland, OR, USA.

Published online: 20 October 2020

\author{
Reference \\ 1. Menza, et al. Prevalence and correlates of transactional sex among \\ women of low socioeconomic status in Portland, OR. BMC Women's \\ Health. 2020;20:219. https://doi.org/10.1186/s12905-020-01088-1.
}

\section{Publisher's Note}

Springer Nature remains neutral with regard to jurisdictional claims in published maps and institutional affiliations. 